\title{
Improved outcome of bilateral compared to single internal thoracic artery grafting: patient's selection or technical skill?
}

\author{
Antonio M. Calafiore ${ }^{1}$, Carlo Maria De Filippo ${ }^{2}$, Massimiliano Foschi $^{2}$, Michele Di Mauro ${ }^{3}$ \\ ${ }^{1}$ Department of Cardiac Surgery, Pope John Paul II Foundation, Campobasso, Italy; ${ }^{2}$ Department of Cardiac Surgery, SS Annunziata Hospital, \\ Chieti, Italy; ${ }^{3}$ Department of Cardiovascular Disease, University of L'Aquila, L'Aquila, Italy \\ Correspondence to: Antonio M. Calafiore, MD. Department of Cardiac Surgery, Pope John Paul II Foundation, Campobasso, Italy. \\ Email: am.calafiore@gmail.com. \\ Provenance: This is a Guest Editorial commissioned by Section Editor Busheng Zhang, PhD, MD (Department of Cardiac Surgery, Shanghai Chest \\ Hospital, Shanghai Jiaotong University, Shanghai, China). \\ Comment on: Iribarne A, Schmoker JD, Malenka DJ, et al. Does Use of Bilateral Internal Mammary Artery Grafting Reduce Long-Term Risk of \\ Repeat Coronary Revascularization? A Multicenter Analysis. Circulation 2017;136:1676-85.
}

Submitted Feb 01, 2018. Accepted for publication Mar 06, 2018.

doi: $10.21037 / \mathrm{atm} .2018 .03 .12$

View this article at: http://dx.doi.org/10.21037/atm.2018.03.12

In this retrospective propensity matched (PM) study Iribarne et al. (1) show again that bilateral internal thoracic artery (BITA) grafting is superior to single internal thoracic artery (SITA) grafting in term of survival and repeat revascularization. The strength of this study is that reports data from the Northern New England Cardiovascular Disease Study Group registry of cardiac surgery including seven centers for a long period of time (22 years). The limitation is that we are missing important information, as BITA targets and any technical detail. Furthermore, it is not clear why patients with single vessel disease were included [which is the benefit in using BITA for the left anterior descending artery (LAD) and diagonal?]. Looking at the unadjusted data, it is evident that BITA was reserved to healthier patients, younger, most likely with less morbidity and better vessel quality. The expected mortality was significantly lower in the BITA group $(0.6 \%$ vs. $1.1 \%$, $\mathrm{P}<0.001)$, mirror of a population with less comorbidity. Nevertheless, in PM patients who represent most likely a low risk population, results were superior in the BITA group, as it happened constantly in observational or PM studies.

The history of BITA grafting is somehow particular. The SITA to LAD was quickly accepted by the surgical world on the basis of an observational study showing better outcomes of the LITA compared to the saphenous vein graft (SVG) when these grafts were anastomosed on the LAD (2). No randomized trial was performed and this strategy was never put in discussion. The same did not happen with BITA, when it was shown in PM patients the superior outcome when BITA was used (3). Even many studies were published, all in favor of BITA grafting $(4,5)$, surgical acceptance of this strategy was very low. The main reason could be that, being the procedure more technical demanding, longer and more exposed to complications (in particular sternal would complications), more data were needed to justify a perceived increased risk of postoperative morbidity. PM studies, being retrospective, are reflecting the real world and the possibility to build two similar groups of patients according to measurable variables allows to include more patients than in randomized studies. However, there are variables which are not measurable and not recorded, as frailty, target vessels quality, grafts quality, perception of the patient's wellness by the surgeon, socioeconomic status, compliance to therapy, and so on. Most of these variables, if none, are not in any data base and then are not included in any study. These biases can be overcome only by randomized studies. However, these latter have their intrinsic problems. Selection criteria can be strict or wide and reflect the thoughts of the team who is planning the study. The risk is that the study group can be not representative of the general population, the danger being to extrapolate the results of a small group of patients to all patients. Moreover, some variable, as vessel quality, is difficult to define and two surgeons can have different visions. With these shortcomings in mind, in front of the many PM studies showing BITA superiority over SITA 
there is only a randomized study, still ongoing, comparing SITA versus BITA, the ART trial, which included only more or less $28 \%$ of the eligible patients (6). In this study the primary outcome was death resulting from any cause at 10 years. At the 5 -year follow-up (7), the rate of death was $8.7 \%$ in the BIMA group and $8.4 \%$ in the SIMA group $(\mathrm{P}=0.77)$, and the rate of the composite of death from any cause, myocardial infarction, or stroke was $12.2 \%$ and $12.7 \%$, respectively $(\mathrm{P}=0.69)$. The limitation of this study is that another arterial conduit, the radial artery (RA) was allowed to be used in $23 \%$ of the SITA patients. Another study based on the same population of the ART trial showed that adding a RA to SITA or BITA was associated with reduced risk of major events (8), complicating the possibility to draw correct conclusions. For this reason, another study was designed, the ROMA trial, which started randomization this year (9).

Is it possible to find a reason why PM studies can constantly differ from randomized trials? Gaudino et al. (5) in a recent meta-analysis, found that in PM studies the benefit in survival was present since the first year, but remained stable at the end of follow-up. As it was unlikely that SVG failure alone could account for this difference, the authors hypothesized that unmeasurable confounders, as patients' general status or quality of the target vessels, could play a role in determining the outcome. We do not think that these variables can justify such a higher mortality during the first year. Looking at the studies included in Gaudino's meta-analysis, the mean age is, in most cases, far below 70 and even less than 60 . The population was, then, in general a young one. We agree with them that unmeasurable confounders can exist, but we think that the main confounder is the technical skill of the single surgeon.

The study from Iribarne et al. (1) underlines once again that the prevalence of BITA grafting in the real world in patients who undergo first time coronary artery bypass grafting $(\mathrm{CABG})$ is very low: $3.1 \%(1,482 / 47,984$ in seven centers) (1). This percentage is related to a long period of time, 22 years, from 1992 to 2014. This means roughly 67 cases per year and more or less 10 cases per center per year, less than 1 per month, to be further divided by the number of surgeons. This percentage is in line with the Society of Thoracic Surgeons (STS) data base report of the last years. Schwann et al. (10) reported STS data from 2004 to 2014, with a prevalence of BITA grafting of 4.1\% (total of 1,307,526 patients with more than one graft operated on in 1,179 centers). The authors reported as well the data from the ANZ (Australia and New Zealand) data base, with a prevalence of $4.3 \%$ (total of 34,213 patients with more than one graft operated on in
24 centers). Interestingly, from these percentages we can assume that in US the prevalence of BITA grafting is more or less 4 per year per center and in Australia and New Zealand is slightly less than 6 per year per center. These small numbers have to be divided by the surgeons working in those centers. In Europe there are no certain data, but very likely the BITA prevalence is below $10 \%$.

We are then talking about a niche surgery, which never reached an amount of cases such to train any cardiac surgeon, at least in US, Australia and New Zealand. Most surgeons do not know how to use the RITA, do not know the best way to use BITA (in situ or Y-graft?), do not know how to skeletonize an ITA. All this just because the number of procedures is so low that surgeons cannot reach the confidence necessary to perform BITA grafting with optimal results. Moreover, the fear of sternal wound complications, especially in countries where cardiac surgery is private, can increase the length of stay and, anyway, the postoperative morbidity. Then, why to spend time in a procedure which is not yet fully accepted? It is better to emphasize the cons rather than to spend time to learn a more complex procedure. The senior author (AMC) in his long career, visited hundreds of centers. In some of them cardiac surgeons were not using magnification higher than 2.5 times, were considering target vessel of $1.5 \mathrm{~mm}$ of diameter small vessels, not grafting anything below $1.5 \mathrm{~mm}$ of diameter. Most surgeons are not accustomed to small anastomoses, then are not able to perform sequentials with ITAs (and often with SVGs). In PM studies the surgeons who are performing BITA grafting are the ones who believe in the superiority of BITA and have learned how to use these conduits in the best way. The surgeons who are using SITA and SVGs often think that coronary surgery has to be reserved to big coronary vessels and that SITA to LAD is the maximum a surgeon has to do for the patient. Then in PM studies BITA grafting is performed by the most skillful surgeons and the SITA supplemented by SVG by the surgeons who are not particularly dedicated to coronary surgery. This is clearly reflected in the paper by Iribarne et al. (1), where the number of distal anastomoses is (median and interquartile range) 3 [3-4] in SITA group and 4 [3-4] in BITA group, $\mathrm{P}<0.001$, mirror most likely of incomplete revascularization. This can justify both the higher survival and the reduced repeat revascularization rate.

When a randomized trial is organized, the centers who participate are the ones with experience in both arms and often the surgeons who are performing routinely BITA have to use SITA and SVGs, using their technical skill in both arms. 
This means that randomized trials select the best centers, the best surgeons, able to graft small vessels and to perform small anastomoses. This aspect, together with the use of RA in the SITA group, most likely will avoid that the ART trial at 10 years will show different results than at 5 years. On the contrary the ROMA trial will show clearly if the attrition rate of SVG is able to have an influence on long term outcome.

However, we can anticipate that the surgical world will remain divided and none, independently from the results of any randomized trial, will abandon his position. It is noteworthy that no study demonstrated the inferiority of BITA over SITA. Then, if there is a possible benefit, why deprive our patients from a possible benefit? Both Iribarne's paper (1) and the ART trial (6) demonstrated that there is a similar 30-day mortality between groups. Sternal wound complications are, in general, higher in the BITA patients $(6,11)$ but Iribarne et al. (1) showed similar prevalence of sternal complication in SITA and BITA patients. Furthermore, Benedetto et al. (12) showed, in a subanalysis of the ART trial, that the prevalence of sternal wound complications, when BITA were harvested as skeletonized conduits, was significantly reduced if compared to pedicled BITA group (9.5\% vs. $16.1 \%, \mathrm{P}=0.018$ ) and was similar to pedicled SITA group (9.5\% vs. $9.6 \%, \mathrm{P}=1.000)$. This means that sternal complications can be reduced.

Lack of appropriate training and fear of complications are, in our opinion, at the basis of low BITA use. These are the unmeasurable confounders which, in our opinion, are present in surgeons' mind more than the long-term benefits related to BITA use.

\section{Acknowledgements}

None.

\section{Footnote}

Conflicts of Interest: The authors have no conflicts of interest to declare.

\section{References}

1. Iribarne A, Schmoker JD, Malenka DJ, et al. Does Use of Bilateral Internal Mammary Artery Grafting Reduce Long-Term Risk of Repeat Coronary Revascularization? A Multicenter Analysis. Circulation 2017;136:1676-85.

2. Loop FD, Lytle BW, Cosgrove DM, et al. Influence of the internal-mammary-artery graft on 10-year survival and other cardiac events. N Engl J Med 1986;314:1-6.

3. Lytle BW, Blackstone EH, Loop FD, et al. Two internal thoracic artery grafts are better than one. J Thorac Cardiovasc Surg 1999;117:855-72.

4. Takagi H, Goto SN, Watanabe T, et al. A meta-analysis of adjusted hazard ratios from 20 observational studies of bilateral versus single internal thoracic artery coronary artery bypass grafting. J Thorac Cardiovasc Surg 2014;148:1282-90.

5. Gaudino M, Di Franco A, Rahouma M, et al. Unmeasured Confounders in Observational Studies Comparing Bilateral Versus Single Internal Thoracic Artery for Coronary Artery Bypass Grafting: A Meta-Analysis. J Am Heart Assoc 2018;7.

6. Taggart DP, Altman DG, Gray AM, et al. Randomized trial to compare bilateral vs. single internal mammary coronary artery bypass grafting: 1-year results of the Arterial Revascularisation Trial (ART). Eur Heart J 2010;31:2470-81.

7. Taggart DP, Altman DG, Gray AM, et al. Randomized Trial of Bilateral versus Single Internal-Thoracic-Artery Grafts. N Engl J Med 2016;375:2540-9.

8. Taggart DP, Altman DG, Flather M, et al. Associations Between Adding a Radial Artery Graft to Single and Bilateral Internal Thoracic Artery Grafts and Outcomes: Insights From the Arterial Revascularization Trial. Circulation 2017;136:454-63.

9. Gaudino M, Alexander JH, Bakaeen FG, et al. Randomized comparison of the clinical outcome of single versus multiple arterial grafts: the ROMA trial-rationale and study protocol. Eur J Cardiothorac Surg 2017;52:1031-40.

10. Schwann TA, Tatoulis J, Puskas J, et al. Worldwide Trends in Multi-arterial Coronary Artery Bypass Grafting Surgery 2004-2014: A Tale of 2 Continents. Semin Thorac Cardiovasc Surg 2017;29:273-80.

11. Buttar SN, Yan TD, Taggart DP, et al. Long-term and short-term outcomes of using bilateral internal mammary artery grafting versus left internal mammary artery grafting: a meta-analysis. Heart 2017;103:1419-26.

12. Benedetto U, Altman DG, Gerry S, et al. Pedicled and skeletonized single and bilateral internal thoracic artery grafts and the incidence of sternal wound complications: Insights from the Arterial Revascularization Trial. J Thorac Cardiovasc Surg 2016;152:270-6.

Cite this article as: Calafiore AM, De Filippo CM, Foschi M, Di Mauro M. Improved outcome of bilateral compared to single internal thoracic artery grafting: patient's selection or technical skill? Ann Transl Med 2018;6(10):189. doi: 10.21037/ atm.2018.03.12 